Xue Yang • Yoko Aoki • Xue Li • Osamu Sakamoto

Masahiro Hiratsuka • Kenneth Michael Gibson

Shigeo Kure · Kuniaki Narisawa • Yoichi Matsubara

Yoichi Suzuki

\title{
Haplotype analysis suggests that the two predominant mutations in Japanese patients with holocarboxylase synthetase deficiency are founder mutations
}

Received: August 31, 2000 / Accepted: September 28, 2000

\begin{abstract}
Holocarboxylase synthetase (HCS) deficiency is a rare autosomal recessive disorder of biotin metabolism. Including three new Japanese patients we diagnosed in this study, ten Japanese families have, so far, been accumulated. In these families, the mutations 237Leu $>$ Pro (seven alleles) and 1067delG (five alleles) were predominant; $508 \mathrm{Arg}>\operatorname{Trp}$ and 550Val $>$ Met mutations were identified in three families in the heterozygous form and in one patient in the homozygous form, respectively. To determine the origin of these mutations, we identified new polymorphic microsatellite markers in the $H C S$ gene and analyzed the haplotypes of the patients. All the 237Leu $>$ Pro and the $1067 \mathrm{delG}$ alleles were associated with haplotype 2-2. This finding is consistent with the notion that these mutations are founder mutations in the Japanese population. Three Japanese 508Arg > Trp alleles were associated with several haplotypes, including 2-3 and 1-4. The haplotype of a Taiwanese patient homozygous for the 508Arg $>\operatorname{Trp}$ mutation was 2-3/2-3. The haplotype of one Japanese patient homozygous for the $550 \mathrm{Val}>$ Met mutation was 1-4/1-4, whereas that of a Jewish patient with the same homozygous mutation was 2-3/2-3. Both mutations were associated with at least two haplotypes and were found in several ethnic groups. The changes 508Arg $>$ Trp and $550 \mathrm{Val}>$ Met occurred at $\mathrm{CpG}$ dinucleotide. The data suggest that these two mutations represent a mutational hot-spot.
\end{abstract}

X. Yang $\cdot$ Y. Aoki $\cdot$ X. Li · O. Sakamoto $\cdot$ M. Hiratsuka $\cdot$ S. Kure Y. Matsubara $\cdot$ Y. Suzuki $(\triangle)$

Department of Medical Genetics, Tohoku University School of Medicine, 1-1 Seiryo-machi, Aoba-ku, Sendai 980-8574, Japan

Tel. +81-22-717-8140; Fax +81-22-717-8142

e-mail: ysuzuki@mail.cc.tohoku.ac.jp

K.M. Gibson

Department of Molecular and Medical Genetics, Oregon Health Sciences University, Portland, OR, USA

K. Narisawa

Faculty of Science and Welfare, Tohoku Bunka Gakuen University, Sendai, Japan
Key words Holocarboxylase synthetase - Multiple carboxylase deficiency · Biotin - Mutation · Microsatellite markers· Haplotype

\section{Introduction}

Holocarboxylase synthetase (HCS: EC 6.3.1.10) is an enzyme that catalyzes biotin incorporation into various carboxylases. Four carboxylases that require biotin as a coenzyme have been identified in mammalian cells: acetylCoA carboxylase (EC 6.4.1.2), a rate-limiting enzyme in fatty acid synthesis; pyruvate carboxylase (EC 6.4.1.1), a key enzyme in gluconeogenesis; propionyl-CoA carboxylase (EC 6.4.1.3), and 3-methylcrotonyl-CoA carboxylase (EC 6.4.1.4), which is involved in amino acid catabolism. Because the biotinylation of these carboxylases is essential for their enzymatic activities, a defect in HCS decreases the activity of several carboxylases, affecting various metabolic processes in cells. HCS deficiency (McKusick 253270) is therefore also referred to as biotin-responsive multiple carboxylase deficiency (MCD). Patients with HCS deficiency have acute episodes of metabolic acidosis and characteristic organic aciduria during the neonatal to early infantile period. Symptoms include tachypnea, feeding difficulties, seizures, and severe dermatitis. Patients may recover from metabolic acidosis within a few days after they start biotin therapy (Wolf 1995).

We isolated human HCS cDNA and have analyzed mutations among Japanese and other ethnic groups of patients with an HCS deficiency (Suzuki et al. 1994; Aoki et al. 1995; Aoki et al. 1999). The mutations 237Leu > Pro (nucleotide change $997 \mathrm{~T}>\mathrm{C}$ ) and $1067 \mathrm{delG}$ predominated only among the Japanese patients. The 508Arg $>\operatorname{Trp}(1809 \mathrm{C}>\mathrm{T})$ mutation has been found in two unrelated Japanese patients (Sakamoto et al. 1998), as well as in non-Japanese patients (Dupuis et al. 1996). The 550Val $>$ Met $(1935 \mathrm{G}>\mathrm{A})$ mutation has also been found in many ethnic groups (Dupuis et al. 1996; Aoki et al. 1997; Zammarchi et al. 1998). To determine the origin of these mutations in 
families with an HCS deficiency, we analyzed the haplotypes of normal and mutant HCS alleles.

\section{Patients and methods}

\section{Patients}

The offspring of non-consanguineous Japanese parents, patient 1 developed severe ketoacidosis on the second day of life and died at the age of 5 days. Organic aciduria typical of MCD was present. HCS activity was assayed as described previously (Suzuki et al. 1996). The enzymatic activity in the patient's liver autopsy sample was $5.0 \%$ of the control value.

Patient 2 is a girl born to unrelated Japanese parents. This patient developed an upper respiratory infection at the age of 8 months that was followed by metabolic acidosis and a skin infection. Because urinary organic acid was indicative of MCD, biotin was administered. Her physical and mental development proceeded normally when she received $40 \mathrm{mg} /$ day of biotin. The HCS activity in lymphoblasts was $14.1 \%$ of the control value.
Patient 3 was also a Japanese girl, the offspring of a nonconsanguineous marriage. She developed severe ketoacidosis on the first postpartum day and died 5 days later. A child of the same parents (is girl) born before her had also died at the age of 4 days. An HCS deficiency was demonstrated by assaying the enzyme activity in fibroblasts from the patient (5.5\% of the control value).

The other patients analyzed in this study have been described elsewhere (for references see Table 1). This study was approved by the Ethics Committee of Tohoku University School of Medicine.

\section{Mutation in HCS-deficient patients}

Genomic DNA from fibroblasts, lymphoblasts, or an autopsy sample was prepared, using a SepaGene Kit (Sanko Junyaku, Tokyo, Japan). DNA was extracted from dried blood spots obtained from the parents, the grandparents, and control individuals, as described (Ogasawara et al. 1994). The $997 \mathrm{~T}>\mathrm{C}(237 \mathrm{Leu}>$ Pro) and the $1067 \mathrm{delG}$ mutations were screened, using polymerase chain reactionrestriction fragment length polymorphism (PCR-RFLP), as described (Aoki et al. 1995). The 508Arg > Trp (1809C >

Table 1. Mutations and haplotypes of patients with holocarboxylase synthetase (HCS) deficiency

\begin{tabular}{|c|c|c|c|c|c|c|}
\hline Family & Individual & $H C S$ mutation & $\begin{array}{l}\text { CAAA } \\
\text { repeat }\end{array}$ & $\begin{array}{l}\text { ATTC } \\
\text { repeat }\end{array}$ & $\begin{array}{l}\text { Haplo- } \\
\text { type }\end{array}$ & Reference \\
\hline \multirow[t]{3}{*}{1 (Japanese) } & Father & $1067 \mathrm{delG}$ & $2 / 2$ & $2 / 2$ & $2-2^{a} / 2-2$ & \multirow[t]{5}{*}{ Patient 1 (present study) } \\
\hline & Mother & 237Leu $>$ Pro & $2 / 2$ & $2 / 2$ & $\overline{2-2} / 2-2$ & \\
\hline & Patient & 1067delG/237Leu $>$ Pro & $2 / 2$ & $2 / 2$ & $\overline{2-2} / 2-2$ & \\
\hline \multirow[t]{3}{*}{2 (Japanese) } & Father & $1067 \mathrm{delG}$ & $2 / 3$ & $2 / 3$ & $2-2 / 3-3$ & \\
\hline & Mother & $?$ & $2 / 2$ & $2 / 3$ & $\overline{2-2} / 2-3$ & \\
\hline & Patient & $1067 \mathrm{delG} / ?$ & $2 / 2$ & $2 / 2$ & $\overline{2-2} / 2-2$ & Patient 2 (present study) \\
\hline \multirow[t]{3}{*}{3 (Japanese) } & Father & large deletion (LD) & $2 / 2$ & $3 / 2$ & $\overline{2-3} / 2-2$ & \\
\hline & Mother & 237Leu $>$ Pro & $2 / 2$ & $2 / 2$ & $\overline{2-2} / 2-2$ & \\
\hline & Patient & LD/237Leu $>$ Pro & $2 / 2$ & $3 / 2$ & $2-3 / 2-2$ & Patient 3 (present study) \\
\hline \multirow[t]{3}{*}{4 (Japanese) } & Father & 237Leu $>$ Pro & $2 / 2$ & $2 / 1$ & $2-2 / 2-1$ & \\
\hline & Mother & 237Leu $>$ Pro & $2 / 2$ & $2 / 4$ & $\overline{2-2} / 2-4$ & \\
\hline & Patient & 237Leu $>$ Pro/237Leu $>$ Pro & $2 / 2$ & $2 / 2$ & $\overline{2-2} / 2-2$ & Patient 1 (Aoki et al. 1995) \\
\hline \multirow[t]{5}{*}{5 (Japanese) } & Father & $1067 \mathrm{delG}$ & $2 / 2$ & $2 / 1$ & $\overline{2-2} / \overline{2-1}$ & \\
\hline & Mother & 237Leu $>$ Pro & $2 / 1$ & $2 / 3$ & $\overline{2-2} / 1-3$ & \\
\hline & Patient & 1067delG/237Leu $>$ Pro & $2 / 2$ & $2 / 2$ & $\overline{2-2} / 2-2$ & Patient 2 (Aoki et al. 1995) \\
\hline & Sister 1 & $1067 \mathrm{delG}$ & $2 / 1$ & $2 / 3$ & $\overline{2-2} / \overline{1-3}$ & \\
\hline & Sister 2 & normal & $2 / 1$ & $1 / 3$ & $\overline{2-1} / 1-3$ & \\
\hline \multirow[t]{3}{*}{6 (Japanese) } & Father & 237Leu $>$ Pro & $2 / 3$ & $2 / 4$ & $2-2 / 3-4$ & \\
\hline & Mother & 508Arg $>$ Trp & $2 / 2$ & $3 / 3$ & $\overline{2-3} / 2-3$ & \\
\hline & Patient & 237Leu $>$ Pro/508Arg $>$ Trp & $2 / 2$ & $2 / 3$ & $\overline{2-2} / 2-3$ & Patient 3 (Aoki et al. 1995) \\
\hline \multirow[t]{4}{*}{7 (Japanese) } & Father & $1067 \mathrm{delG}$ & $2 / 2$ & $2 / 2$ & $\overline{2-2} / \overline{2-2}$ & \\
\hline & Mother & 237Leu $>$ Pro & $\overline{2} / 2$ & $\overline{2} / 4$ & $\overline{2-2} / 2-4$ & \\
\hline & Patient 1 & 1067delG/237Leu $>$ Pro & $2 / 2$ & $2 / 2$ & $\overline{2-2} / 2-2$ & Patient 4a (Aoki et al. 1995) \\
\hline & Patient 2 & 1067delG/237Leu $>$ Pro & $2 / 2$ & $2 / 2$ & $2-2 / 2-2$ & Patient 4b (Aoki et al. 1995) \\
\hline \multirow[t]{3}{*}{8 (Japanese) } & Father & $1067 \mathrm{delG}$ & $2 / 2$ & $2 / 3$ & $2-2 / 2-3$ & \\
\hline & Mother & 508Arg $>$ Trp & $1 / 2$ & $4 / 3$ & $\overline{1-4} / 2-3$ & \\
\hline & Patient & 1067delG/508Arg $>$ Trp & $2 / 1$ & $2 / 4$ & $\overline{2-2} / 1-4$ & Patient 1 (Sakamoto et al. 1998) \\
\hline 9 (Japanese) & Patient & 565 Arg $>$ Ter/508Arg $>$ Trp & $2 / 3$ & $3 / 1$ & $\frac{2-3}{2-1} / \frac{3-1}{3-3}$ or & Patient 2 (Sakamoto et al. 1998) \\
\hline \multirow[t]{3}{*}{10 (Japanese) } & Father & $550 \mathrm{Val}>\mathrm{Met}$ & $1 / 2$ & $4 / 2$ & $1-4 / 2-2$ & \\
\hline & Mother & $550 \mathrm{Val}>\mathrm{Met}$ & $1 / 2$ & $4 / 3$ & $\underline{1-4} / 2-3$ & \\
\hline & Patient & $550 \mathrm{Val}>\mathrm{Met} / 550 \mathrm{Val}>\mathrm{Met}$ & $1 / 1$ & $4 / 4$ & $\overline{1-4} / 1-4$ & (Aoki et al. 1997) \\
\hline 11 (Taiwanese) & Patient & 508Arg $>$ Trp/508Arg $>$ Trp & $2 / 2$ & $3 / 3$ & $\overline{2-3} / 2-3$ & (Hwu et al. 2000) \\
\hline 12 (Jewish) & Patient & $550 \mathrm{Val}>\mathrm{Met} / 550 \mathrm{Val}>\mathrm{Met}$ & $2 / 2$ & $3 / 3$ & $2-3 / 2-3$ & (Livne et al. 1994) \\
\hline
\end{tabular}

${ }^{\mathrm{a}}$ Underlined haplotypes represent mutant alleles 
T), 565Arg $>$ Ter $(1980 \mathrm{C}>\mathrm{T})$ and $550 \mathrm{Val}>\operatorname{Met}(1935 \mathrm{G}$ $>$ A) mutations were determined by direct sequencing, as described (Aoki et al. 1997; Sakamoto et al. 1998).

Analysis of polymorphic markers

Di-, tri-, and tetra-nucleotide repeats were searched for in the genomic region encompassing the $H C S$ gene (accession numbers AP001726 and AP001727), and ten regions were listed as candidate regions for polymorphic markers. Only two fragments were successfully amplified and showed polymorphism. One was located in intron 8 and the other in intron 9 of the $H C S$ gene. These were named the CAAA repeat and the ATTC repeat, respectively. The primer pairs used to amplify each region were: 5'-TCAGCTGTGTGAC AGTGAGACTCTATCT and 5'-GCTGGCATCGCTTC CAACCCAAACACCCAG for the CAAA repeat; $5^{\prime}$-TG ATCCTGCCGACTCCAGTGAAGTATAACC- ${ }^{\prime}$ and 5'-CTTGGTTCACTGATGGCATTCAGAAGTGTG for the ATTC repeat. The PCR reaction mixture of $25 \mu 1$, including $0.4 \mu \mathrm{M}$ each of sense and antisense primers and 1 unit of Taq polymerase (Takara, Tokyo, Japan) proceeded through $30 \mathrm{cycles}$ of $94^{\circ} \mathrm{C}$ for $15 \mathrm{~s}, 70^{\circ} \mathrm{C}$ for $30 \mathrm{~s}$, and $72^{\circ} \mathrm{C}$ for $1 \mathrm{~min}$. The size of the PCR products was estimated using ALF Express II (Amersham Pharmacia Biotech, Uppsala, Sweden), with internal and external DNA standards as recommended by the manufacturer.

\section{Results and discussion}

\section{Mutation analysis in HCS-deficient patients}

Three Japanese patients with deficient HCS activity were screened for the known mutations, 237Leu $>$ Pro, 1067delG, 508Arg $>$ Trp, 565Arg $>$ Ter, and 550Val $>$ Met. The onset of symptoms in patient 1 were typically neonatal, and the 237Leu > Pro and the $1067 \mathrm{delG}$ mutations were identified. This genotype has already been identified in two other families (Table 1). Patient 2 had the $1067 \mathrm{delG}$ mutation in the heterozygous form. Patient 3 had a 237Leu > Pro mutation that was derived from her mother, who is heterozygous for this mutation. Analysis by PCRRFLP showed that this patient had only mutant bands. Her father, however, had only a wild-type band. All coding exons of patient 3 were directly sequenced, but no other mutations were found. These observations suggest that the paternal allele has a large deletion involving at least the exon that contains 237Leu (997T), and that patient 3 was hemizygous for 237Leu > Pro. Among 20 mutant Japanese alleles, the 237Leu $>$ Pro and the 1067delG account for 7 and 5 , respectively. The five mutations screened in this study accounted for $90 \%$ of the mutant alleles in the Japanese population.

Polymorphic markers in the HCS gene

The presence of a polymorphism at the loci of ten candidate regions containing di-, tri-, or tetra-nucleotide repeats was examined in genomic DNA from four individuals. The tetranucleotide CAAA and ATTC repeats were amplified by PCR and showed polymorphic bands. We then examined 50 normal Japanese individuals, using these two markers. All of the PCR products of these two markers were subcloned and sequenced to determine the exact numbers of the repeat. The sequence variations of the fragments obtained from 100 amplified control alleles are shown in Table 2. The numbers of CAAA repeats ranged from 6 to 8 , and those of ATTC repeats ranged from 10 to 15 . The frequency of each type of the two markers is shown in Table 3. The type 2 allele was the most frequent and accounted for $62 \%$ of 100 alleles in the CAAA repeat. Fortysix percent of individuals were heterozygous at this marker. In the ATTC repeat, the type 3 allele was the most frequent $(47 \%)$, and four other types $(1,2,3$, and 5$)$ accounted for about $10 \%$ each of the alleles. Type 6 was found only in one allele examined. Sixty-eight percent of individuals were heterozygous at this marker.

\section{Haplotype of HCS gene with CAAA and ATCC repeats}

Haplotypes determined by a combination of the CAAA and the ATTC are shown in Table 4. Within 100 alleles, 66 were determined with certainty (phase known). Type 2 of

Table 2. Sequences of the CAAA and ATTC repeats

\begin{tabular}{ccll}
\hline Allele type & Length of PCR product & Repeat number & Sequence \\
\hline CAAA & & & \\
1 & $98 \mathrm{bp}$ & 6 & $5^{\prime}$-CAAAA(CAAA) ${ }_{6}$ CTCTCTCAA \\
2 & $102 \mathrm{bp}$ & 7 & $5^{\prime}$-CAAAA(CAAA) ${ }_{7}$ CTCTCTCAA \\
3 & $106 \mathrm{bp}$ & 8 & $5^{\prime}$-CAAAA(CAAA) ${ }_{8}$ CTCTCTCAA \\
ATTC & & & \\
1 & $102 \mathrm{bp}$ & 10 & $5^{\prime}$-ATTT(ATTC) ${ }_{10} \mathrm{CA}$ \\
2 & $106 \mathrm{bp}$ & 11 & $5^{\prime}$-ATTT(ATTC) ${ }_{11} \mathrm{CA}$ \\
3 & $110 \mathrm{bp}$ & 12 & $5^{\prime}$-ATTT(ATTC) ${ }_{12} \mathrm{CA}$ \\
4 & $114 \mathrm{bp}$ & 13 & $5^{\prime}$-ATTT(ATTC) ${ }_{13} \mathrm{CA}$ \\
5 & $118 \mathrm{bp}$ & 14 & $5^{\prime}$-ATTT(ATTC) ${ }_{14} \mathrm{CA}$ \\
6 & $122 \mathrm{bp}$ & 15 & $5^{\prime}$-ATTT(ATTC) ${ }_{15} \mathrm{CA}$ \\
\hline
\end{tabular}

PCR, Polymerase chain reaction 
Table 3. Frequency and genotype of the CAAA and ATTC alleles in 50 control individuals

\begin{tabular}{|c|c|c|c|}
\hline \multirow{2}{*}{\multicolumn{2}{|c|}{$\begin{array}{l}\text { CAAA } \\
\text { Allele frequency }\end{array}$}} & \multirow{2}{*}{\multicolumn{2}{|c|}{ ATTC }} \\
\hline & & & \\
\hline & Frequency (\%) & Allele type & Frequency (\%) \\
\hline 1 & 19 & 1 & 13 \\
\hline 2 & 62 & 2 & 16 \\
\hline \multirow[t]{4}{*}{3} & 19 & 3 & 47 \\
\hline & & 4 & 13 \\
\hline & & 5 & 10 \\
\hline & & 6 & 1 \\
\hline \multicolumn{4}{|l|}{ Genotype } \\
\hline Type & Frequency (\%) & Type & Frequency (\%) \\
\hline $1 / 1$ & 4 & $1 / 1$ & 4 \\
\hline $2 / 2$ & 42 & $2 / 2$ & 4 \\
\hline $3 / 3$ & 8 & $3 / 3$ & 22 \\
\hline $1 / 2$ & 24 & $4 / 4$ & 0 \\
\hline $1 / 3$ & 6 & $5 / 5$ & 2 \\
\hline \multirow[t]{16}{*}{$2 / 3$} & 16 & $6 / 6$ & 0 \\
\hline & & $1 / 2$ & 4 \\
\hline & & $1 / 3$ & 10 \\
\hline & & $1 / 4$ & 2 \\
\hline & & $1 / 5$ & 2 \\
\hline & & $1 / 6$ & 0 \\
\hline & & $2 / 3$ & 14 \\
\hline & & $2 / 4$ & 2 \\
\hline & & $2 / 5$ & 2 \\
\hline & & $2 / 6$ & 2 \\
\hline & & $3 / 4$ & 18 \\
\hline & & $3 / 5$ & 8 \\
\hline & & $3 / 6$ & 0 \\
\hline & & $4 / 5$ & 4 \\
\hline & & $4 / 6$ & 0 \\
\hline & & $5 / 6$ & 0 \\
\hline
\end{tabular}

the CAAA repeat and type 3 of the ATTC repeat (named haplotype 2-3) were the most frequent. Haplotype 2-2 was the second most frequent. Twelve haplotypes were found in our control samples.

We determined the haplotypes of Japanese patients with an HCS deficiency and their parents in ten unrelated families. In addition, we analyzed a Taiwanese patient who is homozygous for $508 \mathrm{Arg}>\mathrm{Trp}$, and a Jewish patient who is homozygous for $550 \mathrm{Val}>$ Met (Table 1). All seven 237Leu > Pro mutant alleles were associated with the 2-2 haplotype. All five 1067delG mutant alleles were also associated with this haplotype. Both the 237Leu $>$ Pro and the $1067 \mathrm{delG}$ seemed to be in linkage disequilibrium with haplotype 2-2, suggesting that they are founder mutations in the Japanese population.

The 508Arg $>$ Trp mutation was found in three unrelated Japanese families. The 508Arg > Trp mutant allele of family 6 was associated with haplotype 2-3, and that of family 8 with haplotype 1-4 (Table 1 ). The haplotype of the patient in family 9 could not be determined unequivocally, but should be different from haplotype 1-4. The homozygous 508Arg > Trp mutation in the Taiwanese patient was associated with haplotype 2-3. The $550 \mathrm{Val}>$ Met mutation was also found in a Japanese patient and in a Jewish patient in the homozygous form (Table 1). The haplotype of the Japanese patient was 1-4/1-4, whereas that of the Jewish patient was 2-3/2-3. The nucleotide change in the $508 \mathrm{Arg}>\operatorname{Trp}$ and the $550 \mathrm{Val}>$ Met mutations is a C-to-T
Table 4. Haplotype of the HCS gene in 66 control alleles

\begin{tabular}{ll} 
Haplotype & \\
CAAA-ATTC & Frequency (\%) \\
\hline $2-3$ & 38 \\
$2-2$ & 17 \\
$1-3$ & 11 \\
$2-5$ & 9 \\
$2-4$ & 9 \\
$3-1$ & 6 \\
$3-4$ & 3 \\
$1-4$ & 1.5 \\
$1-2$ & 1.5 \\
$1-3$ & 1.5 \\
$3-5$ & 1.5 \\
\hline
\end{tabular}

transition at the $\mathrm{CpG}$ dinucleotide, and is found in several ethnic groups (Dupuis et al. 1996; Aoki et al. 1997; Zammarchi et al. 1998). These data are in accord with the notion that 508Arg $>$ Trp and 550 Val $>$ Trp represent hotspot mutations. The spectrum of mutations in Japanese patients is different from that in other ethnic groups (Aoki et al. 1995; Dupuis et al. 1996; Aoki et al. 1999). This is probably because two founder mutations, 237Leu $>$ Pro and 1067delG, have become predominant in the Japanese population.

Acknowledgements We thank Kumi Narita for excellent technical assistance and Michiko Sugawara for expert secretarial assistance. This study was supported by Grants-in-Aid for Scientific Research from the Ministry of Education, Culture, and Science of Japan and by grants from the Ministry of Health and Public Welfare of Japan.

\section{References}

Aoki Y, Li X, Sakamoto O, Hiratsuka M, Akaishi H, Xu L, Briones P, Suormala T, Baumgartner ER, Suzuki Y, Narisawa K (1999) Identification and characterization of mutations in patients with holocarboxylase synthetase deficiency. Hum Genet 104:143-148

Aoki Y, Suzuki Y, Li X, Sakamoto O, Chikaoka H, Takita S, Narisawa K (1997) Characterization of mutant holocarboxylase synthetase (HCS): a $\mathrm{Km}$ for biotin was not elevated in a patient with HCS deficiency. Pediatr Res 42:849-854

Aoki Y, Suzuki Y, Sakamoto O, Li X, Takahashi K, Ohtake A, Sakuta R, Ohura T, Miyabayashi S, Narisawa K (1995) Molecular analysis of holocarboxylase synthetase deficiency: a missense mutation and a single base deletion are predominant in Japanese patients. Biochim Biophys Acta 1272:168-174

Dupuis L, Leon-Del-Rio A, Leclerc D, Campeau E, Sweetman L, Saudubray JM, Herman G, Gibson KM, Gravel RA (1996) Clustering of mutations in the biotin-binding region of holocarboxylase synthetase in biotin-responsive multiple carboxylase deficiency. Hum Mol Genet 5:1011-1016

Hwu W, Suzuki Y, Yang X, Li X, Chou S, Narisawa K, Tsai W (2000) Late-onset holocarboxylase synthetase deficiency with homologous R508W mutation. J Formos Med Assoc 99:174-177

Livne M, Gibson KM, Amir N, Eshel G, Elpeleg ON (1994) Holocarboxylase synthetase deficiency: a treatable metabolic disorder masquerading as cerebral palsy. J Child Neurol 9:170-172

Ogasawara M, Matsubara Y, Mikami H, Narisawa K (1994) Identification of two novel mutations in the methylmalonyl-CoA mutase gene with decreased levels of mutant mRNA in methylmalonic acidemia. Hum Mol Genet 3:867-872

Sakamoto O, Suzuki Y, Aoki Y, Li X, Hiratsuka M, Yanagihara K, Inui K, Okabe T, Yamaguchi S, Kudoh J, Shimizu N, Narisawa K (1998) 
Molecular analysis of new Japanese patients with holocarboxylase synthetase deficiency. J Inherit Metab Dis 21:873-874

Suzuki Y, Aoki Y, Ishida Y, Chiba Y, Iwamatsu A, Kishino T, Niikawa N, Matsubara Y, Narisawa K (1994) Isolation and characterization of mutations in the human holocarboxylase synthetase cDNA. Nat Genet 8:122-128

Suzuki Y, Aoki Y, Sakamoto O, Li X, Miyabayashi S, Kazuta Y, Kondo H, Narisawa K (1996) Enzymatic diagnosis of holocarboxylase synthetase deficiency using apo-carboxyl carrier protein as a substrate. Clin Chim Acta 251:41-52
Wolf B (1995) Disorders of biotin metabolism. In: Scriver CR, Beaudet AL, Sly WS, Valle D (eds) The metabolic and molecular basis of inherited disease. McGraw-Hill, New York, pp 3151-3177

Zammarchi E, Giorgi M, Donati MA, Berlinguer Palmini R, Ciani F, Morrone A (1998) Molecular analysis of the holocarboxylase synthetase gene in an Italian patient with biotin-responsive multiple carboxylase deficiency (abstract). Am J Hum Genet 63:395 